\title{
THE EFFECT OF RATIONAL EMOTIVE THERAPY GROUP COUNSELING ON SELF ESTEEM OF MIDDLE SCHOOL STUDENTS IN SMP NEGERI 27 MEDAN NORTH SUMATRA
}

\author{
Regina BM Nainggolan', Rafael Lisinus Ginting ${ }^{2}$ \\ Institut Agama Kristen Negeri Tarutung ${ }^{1}$ \\ Prodi BK Fakultas Ilmu Pendidikan Universitas Negeri Medan ${ }^{2}$ \\ Email: reginanainggolan187@gmail.com ${ }^{1}$
}

\begin{abstract}
The purpose of this study was to determine the effect of rational emotive therapy group counseling on the self-esteem of grade VIII students at SMP Negeri 27 Medan. The sample in this study amounted to 7 students who have low self-esteem who were found through the purposive sampling technique. This research is a quasi experimental research with pre-post test one group design. The data were collected using a questionnaire called the self-esteem instrument. There were 57 items tested, then obtained 39 valid items and 18 invalid items. Based on the results of calculations using the Cronbach Alpha formula, it is known that r11 $=0.919$ and after being compared with the correlation index, it is concluded that the instrument has very high reliability. Furthermore, the data were analyzed using the Wilcoxon test to see whether there was an effect of rational emotive therapy group counseling on students' self esteem. From the research data, the results of the calculation with the pre-test score in the sample obtained an average $=73.1$ while the post-test score obtained an average $=127.71$. Data analysis using the Wilcoxon level test obtained $J$ count $=13$ while $J$ table $=2$.From the critical value table $J$ for the Wilcoxon cascade test for $n=7, \alpha=0.05$ in accordance with the criteria for acceptance and rejection of the hypothesis, the hypothesis is accepted if $J$ count $>J$ table, namely $J$ count $>J$ table where 13> 2 which means the hypothesis is accepted. The results of this study are expected to be the main input for educators to alleviate problems that arise in students due to low selfesteem.
\end{abstract}

Keywords: Guidance and Counseling; Group Counseling; Rational Emotional Therapy; Self Esteem

PENDAHULUAN

Kebutuhan self esteem merupakan

kebutuhan seseorang untuk merasakan bahwa dirinya adalah seseorang yang patut dihargai dan dihormati sebagai manusia yang baik. Seliap individu normal pasti berharap dan menginginkan dapat merasakan hidup sukses, dihormati dan dihargai sebagai manusia.

Menurut Baron \& Byrne (2003) "Self esteem adalah komponen evaluatif dari konsep diri dalam rentang dimensi positif-negatif". Menurut Maslow (dalam Hambali dan Jaenudin, 2013: 180-183) bahwa setiap manusia memiliki lima kebutuhan dasar yaitu kebutuhan fisiologis, rasa aman, cinta, harga diri, kognitif, estetika dan aktualisasi diri. Harga diri merupakan salah satu kebutuhan penting bagi manusia. Berdasarkan hirarki kebutuhan Abraham Maslow, kebutuhan akan penghargaan (esteem needs) mendapatkan tempat ke 4, yang artinya jika kebutuhan ini tidak dipenuhi maka kebutuhan dibawahnya (aktualisasi diri) pun tidak akan terpenuhi. Kebutuhan ini mencakup penghormatan diri, kepercayaan diri, kemampuan, dan pengetahuan yang orang lain hargai tinggi. Penghargaan diri dapat dilihat sebagai karakteristik kepribadian disfungsional yang terbentuk sangat awal dalam hidup dan mempengaruhi perkembangan selanjutnya. Siswa yang memiliki self 
esteem rendah berorientasi negatif terhadap pemecahan masalah dan meningkatkan kemungkinan terjadinya kemarahan dan permusuhan, selain itu siswa yang memiliki self esteem rendah merupakan indikasi dari kepribadian yang tidak berfungsi normal, selalu berfikiran negatif tentang permasalahn dalam hidup karena tidak mampu menghadi kenyataan atau segala konsekuensi (Mruk, 2006:84). Siswa yang memiliki self esteem tinggi akan membangkitkan rasa percaya diri, rasa yakin akan kemampuan diri, rasa berguna serta rasa bahwa kehadirannya diperlukan di dunia ini. Selain itu remaja juga memiliki kepercayaan diri dapat mencapai prestasi yang dia dan orang lain harapkan. Pada tahapannya, keyakinan itu akan memotivasi remaja tersebut untuk sungguh-sungguh mencapai apa yang dicita-citakan. Sementara itu remaja dengan self esteem rendah akan lebih rentan berperilaku negatif karena self esteem dapat mempengaruhi perilaku seseorang (Clemes, dkk., 2012: 3).

Menurut Mruk (2006:84) "research shows that those who live this type of low self-esteem tend to reject positive feedback, focus on negative information about themselves, avoid risk, and so forth" yang artinya "penelitian menunjukkan bahwa mereka yang hidup dengan harga diri rendah cenderung menolak umpan balik positif, fokus pada informasi negatif tentang diri mereka sendiri, menghindari risiko, dan sebagainya ".

Studi pendahuluan yang dilakukan penulis di SMP Negeri 27 Medan kelas VIII7 dengan membagikan angket selfesteem kepada 38 orang siswa. dari hasil angket yang sudah diberikan kepada 38 orang siswa tersebut, ditemukan bahwa terdapat $13,15 \%$ atau 5 siswa yang termasuk dalam kategori kurang, 73,68 \% atau 28 siswa yang termasuk dalam kategori cukup, dan hanya terdapat 13,15 $\%$ atau 5 siswa yang termasuk dalam kategori baik. Berdasarkan hasil angket dapat disimpulkan bahwa masih banyak siswa yang tidak memiliki self esteem dalam kategori baik. Rendahnya self esteem yang dimiliki oleh siswa tersebut menjadikan siswa tersebut berperilaku irasiaonal atau dapat dikatan berperilaku tidak wajar hal itu telah dikemukakan oleh Messina (2007) tentang ciri-ciri individu yang memiliki self esteem yang rendah. Menurutnya individu yang memiliki self esteem rendah menganggap diri mereka lebih rendah dari orang lain, lebih mudah gusar, memudarnya hasrat untuk belajar, depresi, merasa dirinya tidak berharga, berfikir irasional, kurang mampu memecahkan masalah dan mudah takut.

Lebih lanjut, berdasarkan hasil wawancara dengan guru BK penulis 
menyimpulkan beberapa masalah yang terdapat pada siswa yang terdapat beberapa siswa yang menyatakan gagal sebelum mencoba, Siswa yang beranggapan temannya lebih baik dari dirinya, terdapat Siswa yang tidak mandiri, Siswa yang menjauhkan diri dari temannya, Siswa yang marah ketika dikritik temannya, namun ada juga siswa yang tampak ketergantungan terhadap temannya.

Peranan guru bimbingan dan konseling adalah mendampingi siswa dalam beberapa hal, antara lain dalam perkembangan belajar/akademis, mengenal diri sendiri, dan peluang masa depan mereka, menentukan cita-cita dalam tujuan hidupnya, dan menyusun rencana yang tepat untuk mencapai tujuan-tujuan itu, serta mengatasi masalah pribadi. Pendekatan konseling yang diperkirakan tepat dalam meningkatkan self esteem siswa adalah Rational Emotif Therapy (RET).

\section{Menurut Ellis Rational Emotive} Therapy berusaha membelajarkan kembali konseli untuk memahami input kognitif yang menyebabkan gangguan emosional, mengubah pikiran konseli agar membiarkan pikiran irasionalnya atau belajar mengantisipasi manfaat atau konsekuensi dari tingkah laku. Hal itu menjelaskan bahwa Rational Emotive
Therapy dapat mengatasi masalah self esteem (harga diri) yang rendah. Selain itu terdapat pula pertimbangan mengapa teknik ini digunakan yaitu ekonomis dari segi waktu dan dana serta tepat digunakan karena cocok untuk bermacam-macam konseling.

Dengan layanan konseling kelompok dengan pendekatan rational emotive Therapy ini, siswa diharapkan mampu memenuhi kebutuhannya serta mengatasi masalah-masalah yang dialaminya khususnya masalah didalam dirinya yaitu self esteem.

\section{METODE PENELITIAN}

Penelitian ini adalah eksperimen semu dengan pendekatan kuantitatif yaitu suatu tindakan yang dirancang untuk menyelidiki dengan prosedur ilmiah, menggunakan metode tertentu, untuk memperoleh jawaban atas pertanyaan penelitian melalui data yang dikumpulkan (Asih Menanti, 2010: 28).

Desain yang digunakan dalam penelitian ini adalah One group pre-test post-test design. Populasi adalah seluruh siswa-siswi kelas VIII $^{7}$ di SMP Negeri 27 Medan tahun ajaran 2019/2020 yang berjumlah 37 orang. Besaran Sampel dalam penelitian ini ditentukan melalui teknik purposive sampel. Dari 37 jumlah popolasi maka ditentukan 7 orang siswa yang memiliki self esteem rendah melalui 
screening berdasarkan hasil wawancara dengan Guru BK.

Pengumpulan data dilakukan melalui angket yang disusun sendiri oleh peneliti berdasarkan pada aspek dengan pernyataan tertulis yang digunakan untuk memperoleh data dari responden mengenai self esteem dengan penilaian mengacu pada skala likert. Dari penyataan yang diajukan memiliki sifat favorable (mendukung) dan unfavorable (tidak mendukung). Setiap pertanyaan memiliki 4 alternatif jawaban yaitu : Sangat Sesuai (SS), Sesuai (S), Tidak Sesuai (TS), dan Sangat Tidak Sesuai (STS).

Untuk pertanyaan yang besifat favorable diberi rentang nilai 4-1, dan untuk pertanyaan yang bersifat unfovarable diberi rentang skor 1-4 Adapun aspek yang diukur adalah power, significance, virtue dan competence, dengan jumlah butir itam pernyataan sebanyak 39 item dengan $r_{11}=0,919$

\section{HASIL PENELITIAN}

Langkah awal yang dilakukan peneliti adalah melakukan penjajakan dan identifikasi terhadap masalah yang akan diteliti dengan melakukan screening. Selanjutnya peneliti memberi skala self esteem siswa kepada 7 siswa yang memiliki kriteria rendah sebagai subjek penelitian sebelum diberikan layanan konseling kelompok dengan pendekatan rational emotive therapy untuk melihat pengaruh sebelum dan sesudah diberikan layanan konseling kelompok dengan pendekatan rational emotive therapy. Berdasarkan pre-test maka diperoleh data sebagai berikut:

Tabel 1. Hasil Pre-test Self Esteem Siswa

\begin{tabular}{|c|l|l|c|}
\hline NO & \multicolumn{1}{|c|}{ Nama Siswa } & Skor & Kriteria \\
\hline 1 & MEG & 74 & Rendah \\
\hline 2 & ST & 72 & Rendah \\
\hline 3 & N & 76 & Rendah \\
\hline 4 & ZA & 72 & Rendah \\
\hline 5 & S & 72 & Rendah \\
\hline 6 & DA & 76 & Rendah \\
\hline 7 & SS & 74 & Rendah \\
\hline & Jumlah Nilai & 516 & \\
\hline & Nilai Tertinggi & 76 & \\
\hline & Nilai Terndah & 72 & \\
\hline & Nilai Rata-Rata & 73,71 & \\
\hline & Standar deviasi & 1,79 & \\
\hline
\end{tabular}

Setelah diberikan layanan konseling kelompok dengan pendekatan rational emotive therapy, maka diperoleh hasil perhitungan dengan jumlah responden 7 siswa. Berdasarkan analisis post-test maka diperoleh data sebagai berikut.

Tabel 2. Hasil Post-Test Self Esteem Siswa

\begin{tabular}{|l|l|l|c|}
\hline NO & Nama Siswa & Skor & Kriteria \\
\hline 1 & MEG & 112 & Sedang \\
\hline 2 & ST & 121 & Tinggi \\
\hline 3 & N & 137 & Tinggi \\
\hline 4 & ZA & 139 & Tinggi \\
\hline 5 & S & 136 & Tinggi \\
\hline 6 & DA & 115 & Sedang \\
\hline 7 & SS & 134 & Tinggi \\
\cline { 1 - 2 } Nilai Tertinggi & 139 & \multirow{2}{|c|}{} \\
\cline { 1 - 2 } Nilai Terendah & 112 & \\
\cline { 1 - 2 } Nilai Rata-Rata & 127,71 & \\
\cline { 1 - 2 } \multicolumn{2}{|c|}{ Standar deviasi } & 11,36 & \\
\cline { 2 - 3 } &
\end{tabular}

Berdasarkan tabel 1 dan 2 dapat dilihat bahwa skor rata-rata dalam pre-test 
lebih rendah daripada skor rata-rata post test, yaitu 73,1 < 127,71. Jadi dapat disimpulkan bahwa ada peningkatan self esteem siswa dari rendah menjadi sedang dan tinggi setelah diberikan layanan konseling kelompok dengan pendekatan rational emotive therapy. Rata rata perubahan interval self esteem pada 7 orang siswa tersebut adalah 54 atau sebesar $73,8 \%$. Perubahan self esteem siswa terendah pada MEG sebesar 51,35\% dan perubahan tertinggi pada ZA sebesar $93,06 \%$.

Sebelum dilakukan pengujian hipotesis terlebih dahulu dicari mean beda dan simpangan baku beda. Pengujian hipotesis dilakukan dengan menggunakan uji Wilcoxon, lebih lengkapnya sebagai berikut.

Tabel 3. Hasil Uji Wilcoxon

\begin{tabular}{|c|c|c|c|c|c|c|c|}
\hline $\begin{array}{c}\text { Respon } \\
\text { den }\end{array}$ & $\begin{array}{c}\text { Pre-Test } \\
\text { (XA) }\end{array}$ & $\begin{array}{c}\text { Post-Test } \\
\text { (XB) }\end{array}$ & $\begin{array}{c}\text { Beda } \\
\text { (D) }\end{array}$ & $\begin{array}{c}\text { D-Md } \\
\text { (d) }\end{array}$ & Peringkat & \multicolumn{2}{|c|}{ Tanda Peringkat } \\
\cline { 5 - 8 } & & & & & + & $\cdot$ \\
\hline $\mathbf{1}$ & 74 & 112 & 38 & -14 & $\mathbf{5}$ & & $\mathbf{5}$ \\
\hline $\mathbf{2}$ & 72 & 121 & 49 & -13 & $\mathbf{4}$ & & $\mathbf{4}$ \\
\hline $\mathbf{3}$ & 76 & 137 & 61 & 9 & $\mathbf{2 , 5}$ & $\mathbf{2 , 5}$ & \\
\hline $\mathbf{4}$ & 72 & 139 & 67 & 8 & 1 & 1 & \\
\hline $\mathbf{5}$ & 72 & 136 & 64 & 17 & $\mathbf{7}$ & $\mathbf{7}$ & \\
\hline $\mathbf{6}$ & 76 & 115 & 39 & -16 & $\mathbf{6}$ & & $\mathbf{6}$ \\
\hline $\mathbf{7}$ & 74 & 134 & 60 & 9 & $\mathbf{2 , 5}$ & $\mathbf{2 , 5}$ & \\
\hline$\Sigma X$ & 516 & 894 & 378 & & & $\mathbf{1 3}$ & $\mathbf{1 5}$ \\
\hline
\end{tabular}

Dari tabel di atas terdapat nilai terkecil yaitu 13 , jadi $\mathbf{J}_{\text {hitung }}=13$, dengan $\alpha=0,05$ dan $\mathrm{n}=7$ sehingga nilai $\mathrm{J}_{\text {tabel }}$ adalah 2. Dari data tersebut terlihat bahwa $\mathbf{J}_{\text {hitung }}>\mathbf{J}_{\text {tabel }}$ dimana $13>2$. Jadi dapat disimpulkan bahwa "Ada pengaruh layanan konseling kelompok dengan pendekatan rational emotive therapy terhadap self esteem siswa kelas VIII $^{7}$ SMP Negeri 27 Medan.

\section{PEMBAHASAN}

Berdasarkan hasil penelitian ini, bahwa hipotesis penelitian diterima, artinya terdapat pengaruh dari layanan konseling kelompok dengan pendekatan rational emotive therapy terhadap self esteem siswa kelas VIII $^{7}$ SMP Negeri 27 Medan tahun ajaran 2019/2020. Hal ini telah ditunjukan dari hasil perhitungan uji wilcoxon yaitu $\mathrm{J}_{\text {hitung }}>\mathrm{J}_{\text {tabel }}$ dimana $13>$ 2. Berdasarkan analisis secara keseluruhan pada 7 orang responden terjadi peningkatan self esteem siswa, dari hasil tersebut dapat dilihat pada tes awal (pretest) diperoleh skor rata-rata self esteem siswa 73,1 dan setelah pemberian layanan konseling kelompok dengan pendekatan rational emotive therapy (post-test) diperoleh rata rata 127,71 maka selisih skor rata-rata adalah 54 . Hal ini berarti rata-rata skor self esteem siswa lebih rendah sebelum mendapatkan layanan konseling kelompok dengan pendekatan rational emotive therapy dibandingkan dengan rata rata skor self esteem siswa setelah diberikan layanan konseling kelompok dengan pendekatan rational emotive therapy. 
Pelaksanaan layanan konseling kelompok dengan pendekatan rational emotive therapy ini untuk memperoleh perilaku yang diharapkan, mengeliminasi perilaku yang maladaptif dan memperkuat serta mempertahankan perilaku yang diinginkan

Berdasarkan tahapan yang dikemukakan oleh Rosdjidan (Komalasari dkk, 2016: 157-160) mengenai tahapan konseling kelompok dengan pendekatan rational emotive therapy maka peneliti telah melaksanakan semua tahapan dengan baik. Dengan adanya tahapantahapan konseling kelompok dengan pendekatan rational emotive therapy maka konseling kelompok dengan pendekatan rational emotive therapy yang dilakukan berjalan lebih terarah dan efektif.

Demikian pula dengan self esteem siswa, menurut Baron dan Byrne (2002:173) self esteem adalah evaluasi diri yang dibuat oleh setiap individu tentang dirinya sendiri dalam dimensi positif dan negatif. Secara lebih spesifik dapat diartikan dengan kemampuan dalam membuat harga diri. Siswa yang dijadikan subjek dalam penelitian ini adalah mereka yang tidak mampu membuat penilaian terhadap dirinya sendiri dalam rentang positif atau negatif sehingga dapat dikategoikan sebagai siswa yang kurang menghargai dirinya sendiri.
Setelah siswa yang memiliki self esteem rendah tersebut diberikan layanan konseling kelompok dengan pendekatan rational emotive therapy terjadi peningkatan terhadap self esteem pada siswa sehingga dapat dikatakan penerapan konseling kelompok dengan pendekatan rational emotive therapy berhasil dilakukan. Hal ini sesuai dengan tujuan dari konseling kelompok dengan pendekatan rational emotive therapy menurut Walker \& Shea (Komalasari dkk, 2016: 141) bahwa setiap tingkah laku dapat dipelajari, tingkah laku lama dapat diganti dengan tingkah laku baru, dan manusia memiliki potensi untuk berperilaku baik atau buruk, tepat atau salah. Manusia juga dipandang sebagai individu yang mampu melakukan refleksi atas tingkah lakunya sendiri, mengatur dan mengontrol perilakunya dan dapat belajar tingkah laku baru atau dapat mempengaruhi perilaku orang lain.

\section{PENUTUP}

Hasil analisis data yang diperoleh dalam penelitian ini adalah nilai $\mathrm{J}_{\text {hitung }}=$ 13 dengan $\alpha=0,05$ dan $n=7$, sehingga nilai $\mathrm{J}_{\text {tabel }}$ adalah 2. Dari data tersebut terlihat bahwa $\mathbf{J}_{\text {hitung }}>\mathrm{J}_{\text {tabel }}$ dimana $13>2$. Data pre-test self esteem siswa menunjukkan rata-rata angka sebesar 73,1 dan rata-rata post-test diperoleh skor 127,71 dengan selisih 54,61. Artinya skor 
rata-rata self esteem siswa setelah mendapat layanan konseling kelompok dengan pendekatan rational emotive therapy lebih tinggi dari pada sebelum mendapat layanan konseling kelompok dengan pendekatan rational emotive therapy. Perubahan peningkatan interval self esteem siswa setelah diberikan layanan konseling kelompok dengan pendekatan rational emotive therapy sebesar 73,2 \%. Hal ini menunjukan ada pengaruh layanan konseling kelompok dengan pendekatan rational emotive therapy terhadap self esteem siswa SMP Negeri 27 Medan atau hipotesis diterima.

Berdasarkan kesimpulan di atas, maka sebagai tindak lanjut penelitian ini disarankan hal-hal sebagai berikut: Guru BK agar mempertimbangkan penggunaan layanan konseling kelompok dengan pendekatan rational emotive therapy terhadap self esteem siswa yang rendah. Diharapkan siswa lebih serius dalam mengikuti layanan-layanan bimbingan dan konseling di sekolah yang diberikan oleh guru BK, agar siswa dapat mengantisispasi permasalahanpermasalahan sosial dan pribaadinya. Mengingat bahwa layanan konseling kelompok dengan pendekatan rational emotive therapy dalam mengubah self esteem siswa, maka diharapkan kepala sekolah dapat terus mendukung para guru terutama guru BK dalam hal menjalankan layanan konseling kelompok dengan pendekatan rational emotive therapy. Diharapkan sekolah berperan aktif dalam memfasilitasi kegiatan layanan bimbingan konseling di sekolah agar tujuan yang diharapkan lebih maksimal lagi. Bagi orang tua diharapkan lebih memperhatikan anak anaknya dalam hal keyakinan diri akan kemampuannya dalam belajar. Bagi peneliti selanjutnya, semoga dapat menjadi bahan referensi dan menambah wawasan dalam melakukan penelitian selanjutnya, serta melakukan penelitian lebih lanjut self esteem.

\section{REFERENSI}

Adhiputra, A.A Ngurah, Konseling Kelompok, Yogyakarta: Media.

Ahmad Ali Rahmadian. 2011. Kreativitas dalam Konseling. Proseding Workshop Contemporary and Creative Counseling. Bandung, 2011.

Arikunto, Suharsimi. 2010. Prosedur Penelitian Suatu Pendekatan Praktik. Jakarta: Rineka Cipta.

Aturdian Pramesti. 2015. Hubungan antara self esteem terhadap prestasi belajar mata pelajaran makanan kontinental pada siswa jurusan tata boga kosentrasi jasa boga SMK negeri 1 Sewon. Fakultas Teknik Universitas Negeri Yogyakarta untuk Memenuhi Sebagian Persyaratan Guna Memperoleh Gelar Sarjana Pendidikan. Skripsi. Tidak Dipublikasikan. 
Baron, R, A, 2003. Psikologi Sosial .Jakarta : PT Gelora Aksara Pratama.

Clemes, Haris, Bean, Reynol, dan Clark, Aminah, 1995. Bagaimana Meningkatkan Harga Diri Remaja. Terjemahan oleh Dra. Med. Meitasari Tjandarasa. Jakarta. Binaputra Aksara.

Corey, Gerald. 1988, Teori dan Praktek Kon-seling dan Psikoterapi, Bandung, PT. Eresco.

2005. Teori dan praktek dari konseling dan psikoterapi. Terjemahan oleh E. Koeswara. Jakarta: ERESCO.

Dariuszky, Goran. 2004. Membangun Harga Diri. Bandung: Pionir Jaya.

Field, L, 2003. Self Esteem For Women (Panduan Praktis Bagi Wanita Untuk Mencapai Kesuksesan Dalam Cinta, Karier, Keluarga). Bandung : Penerbit Kaifa.

Goode,C,B， 2005. Optimizing Your Chil'ds Talent. Jakarta: PT Buhana Ilmu Populer.

I Wayan Handika, Dewi Arum, Widhiyanti, MertaPutri, NiKetutSuarni. 2014. Penerapan Konseling Rasional Emotif Dengan Formula ABC Untuk Meningkatkan Percaya Diri Siswa kelas VIII ${ }^{2}$ SMP Laboratorium Undiksha 2013/2014”. Bali: e-journal Undiksa Jurusan Bimbingan Konseling Volume: 2 No 1, Tahun2 014.

Jahja, Yudrik. 2011. Psikologi Perkembangan. Jakarta: Prenada Media.
Kurnanto, E (Ed.). 2013. Konseling Kelompok. Bandung: Alfabeta.

Lumongga Lubis Namora. 2011. Memahami Dasar-Dasar Konseling Dalam Teori Dan. Praktik, Jakarta: Kencana Prenada Media Grup.

Mruk, Christopher J. 2006. Self-esteem Research, Theory, and Practice Toward a Positive Psychology of sel-esteem 3rd Edition. New York: Manufacturing Group.

Prayitno \& Amti, Erman. 2004. Dasardasar Bimbingan dan Konseling. Jakarta: Rineka Cipta.

Willis, Sofyan. S. 2013. Psikologi Pendidikan. Bandung: Alfabeta. 